\title{
On Cultural Connections
}

\author{
Loren Davis \& David Madsen
}

In response to "The Pre-Clovis Peoples" (Vol. 5, No. 2).

To the editors:

In his review, Yuichi Nakazawa provides timely perspectives on the recently published report of human occupation in western Idaho at $\sim 16,000 \mathrm{cal}$. BP. ${ }^{1}$ While we agree with what Nakazawa says, we would like to comment on some aspects that will help to clarify the larger picture of what our research at Cooper's Ferry might mean for the topic of the Pleistocene peopling of the Americas.

Research efforts to identify the timing of initial migration and geographic origins of the first Americans rely heavily on two main lines of evidence:

1. early human skeletal remains from which DNA can be extracted and which, in turn, inform paleogenomic studies tracing the relatedness of both prehistoric and modern human populations; and

2. archaeological assemblages of artifacts, animal and plant remains, and other traces of past human activity, such as fire hearths, pit features, etc., at a site. These provide typological and chronological evidence of the relatedness of human groups.

The Cooper's Ferry site record contains evidence of the latter type. Our study states that some of the late Pleistocene-aged stone tools found at the site were shaped in ways that are similar to somewhat older artifacts from sites found in the Japanese island of Hokkaido and that this similarity may "signal a cultural connection with Upper Paleolithic northeastern Asia."2 This is a broad statement that merely reflects the starting point of a potential line of scientific inquiry. These archaeological connections, whatever they are, are intriguing and worth further investigation.

We were initially attracted to this line of inquiry for the simple reason that there is no other suitable technological progenitor in northeastern Asia or Beringia other than what we see in the contents of the Upper Paleolithic sites of Japan and the string of islands stretching from northern Japan to northeastern Siberia that once formed the Paleo-Sakhalin-Hokkaido-Kuril peninsula. Nakazawa is correct to advise caution in our efforts to explore these similarities in stone tool forms. His proposal is a good one: a well-balanced approach to this issue, including multiple working hypotheses, could determine whether these observed similarities are truly homologous, represent the operation of evolutionary convergence, or show patterns of cultural drift. We look forward to working with an international group of scientists to integrate this approach in future research.

\section{Loren Davis \& David Madsen}

Loren Davis is Professor of Anthropology at Oregon State University and Director of the Pacific Slope Archeological Laboratory.

David Madsen is a Research Fellow at the Texas Archaeological Research Laboratory, University of Texas, and an Adjunct Professor of Anthropology at Texas A\&M University, Texas State University, and Lanzhou University.

1. Loren Davis et al., "Late Upper Paleolithic Occupation at Cooper's Ferry, Idaho, USA, 16,000 Years Ago," Science 365, no. 6,456 (2019): 891-97, doi:10.1126/science.aax9830.

2. Davis et al., "Late Upper Paleolithic Occupation at Cooper's Ferry," 895. 